\title{
Feasibility of Transoral Thyroidectomy by Vestibular Approach
}

\author{
Kshitij Shah, ${ }^{1}$ Shivali Patekar, ${ }^{1}$ Tejal Patel, ${ }^{1}$ Renuka Bradoo ${ }^{1}$
}

Introduction

\section{ABSTRACT}

An open approach to thyroidectomies through neck provides good exposure and safe dissection however, the patient still has a scar. Endoscopic thyroid surgery has been practised since the late 90s. The latest addition is the transoral endoscopic thyroidectomy by vestibular approach.

Materials and Methods

We at our centre performed this surgery on 3 patients. Here we present our initial experience of transoral endoscopic thyroidectomy by vestibular approach (TOETVA).

Results

Two of the three patients did not have any complication. Diffuse bleeding was encountered during one instance and decision was taken to convert it into an open procedure.

Conclusion

The preliminary experience of transoral thyroidectomy by vestibular approach shows it to be a feasible and promising 'scarless' and 'minimally invasive' surgery.

$\underline{\text { Keywords }}$

Thyroidectomy; Endoscopic, transoral

$\mathrm{T}$ he history of thyroid surgery dates back to millennia. Abu al-Qasim is credited with performing the first goitre excision as recorded in his surgical tome, "Al-Tasrif", in 952 AD. ${ }^{1}$ From then thyroid surgery was condemned for most of its history. Surgeons across the world described thyroid surgery as 'one of the most thankless, most perilous undertakings which, if not altogether prohibited, should at least be restricted, dismissing such operations as 'foolhardy performances' and as 'horrid butchery ... deserving of rebuke and condemnation'. It was the likes of Billroth, Kocher and Halstead that resolved the difficulties of modern thyroid surgery and thyroid surgery became one of the most widely practised surgeries across the globe. We have come a long way from the traditional staged thyroid surgeries to the use of robotics in the modern era.

The complications of haemorrhage, post-operative tetany and injury to the recurrent laryngeal nerve abound previously, are a rare occurrence now. Since these complications have been minimised the main focus is now on cosmesis and thus 'scarless' thyroid surgery. The endoscopic thyroid surgery has been in practice since
1996. ${ }^{2}$ The endoscopic approaches can be classified as direct, wherein the access is via an incision over the neck, and the remainder of the surgery is carried using endoscopic instruments and indirect (extra-cervical) which include the trans axillary, postauricular, areolar and transoral approaches. The direct approach, since it involves an incision over the neck, is not truly scarless.

The trans axillary, postauricular, and areolar approaches although leaving no visible scar, involve a significant extent of dissection to reach the site of pathology. ${ }^{3}$ The transoral approach, on the other hand, is truly scarless and involves minimal dissection thus emerging as the most feasible option amongst all described previously. Here we present our early experience of cases of transoral thyroidectomy done by the vestibular approach.

1 - Department of ENT \& HNS, Lokmanya Tilak Municipal Medical College and General Hospital, Sion, Mumbai

Corresponding author:

Dr Shivali Patekar

email: shivalip1990@gmail.com 
Table I: Details of the patients selected for transoral thyroidectomy

\begin{tabular}{|c|c|c|c|c|}
\hline PATIENT & AGE/SEX & $\begin{array}{c}\text { FINE NEEDLE } \\
\text { ASPIRATION } \\
\text { CYTOLOGY } \\
\text { (BETHESDA) }\end{array}$ & $\begin{array}{c}\text { ULTRASONOGRAPHIC } \\
\text { FINDINGS }\end{array}$ & $\begin{array}{c}\text { THYROID FUNCTION } \\
\text { TEST }\end{array}$ \\
\hline 1 & $19 /$ Female & Grade II & $\begin{array}{c}3.0 \times 2.5 \times 1.7 \mathrm{~cm} \text { nodule in } \\
\text { Left lobe }\end{array}$ & Within Normal Limit \\
\hline 2 & $22 /$ Female & Grade II & $\begin{array}{c}4.0 \times 2 \times 2.2 \mathrm{~cm} \text { nodule in } \\
\text { Right lobe }\end{array}$ & Within Normal Limit \\
\hline 3 & $26 /$ Female & Grade IV & $\begin{array}{c}3.3 \times 2.4 \times 2.5 \mathrm{~cm} \text { nodule in } \\
\text { Right lobe }\end{array}$ & Within Normal Limit \\
\hline
\end{tabular}

\section{Materials and Methods}

The procedure was done on three selected patients in the department of ENT and Head and Neck surgery in our hospital. (Table I)

\section{Pre-operative preparation:}

Adequate oral hygiene was ensured for all patients. Oral chlorhexidine gargles was advised. Prophylactic intravenous antibiotics (Cefotaxime and Metronidazole) were started the day prior to surgery and an Informed consent was taken.

\section{Procedure:}

The procedure was carried under general anaesthesia using Nasotracheal intubation with north pole endotracheal tube. The patients were positioned supine with an extension of the neck to have the chin and the thyroid cartilage at the same level.

The oral cavity was rinsed with chlorhexidine mouth wash. Local infiltration using 1:100000 salineadrenaline solution was given at the oral vestibule. A $3 \mathrm{~cm}$ incision was made just above the lower fornix vestibuli. Dissection was continued in the subcutaneous plane till the mandible. A subplatysmal plane was created using a blunt dilator from the mandible to the suprasternal notch, and a $10 \mathrm{~mm}$ trocar was inserted. 2 vertical incisions were given, one on each side of the central incision, each $5 \mathrm{~mm}$ in length and a $5 \mathrm{~mm}$ trocarwere inserted on each side. (Fig. 1)
$\mathrm{A} 30^{\circ}$ telescope was introduced through the $10 \mathrm{~mm}$ port, and the $5 \mathrm{~mm}$ side ports were used for instrumentation. $\mathrm{CO} 2$ was insufflated at $6 \mathrm{mmHg}$ pressure. Externally a stitch was taken at the level of the hyoid to elevate the subcutaneous plane if required. The strap muscles were identified and retracted laterally. The affected lobe was devascularised and dissected laterally from the trachea-oesophageal groove using a Ligasure ${ }^{\mathrm{TM}}$ device. The isthmus was then separated from the underlying pretracheal fascia. The specimen was removed from the $10 \mathrm{~mm}$ port using an endobag with a purse-string suture. After achieving haemostasis the strap muscles were

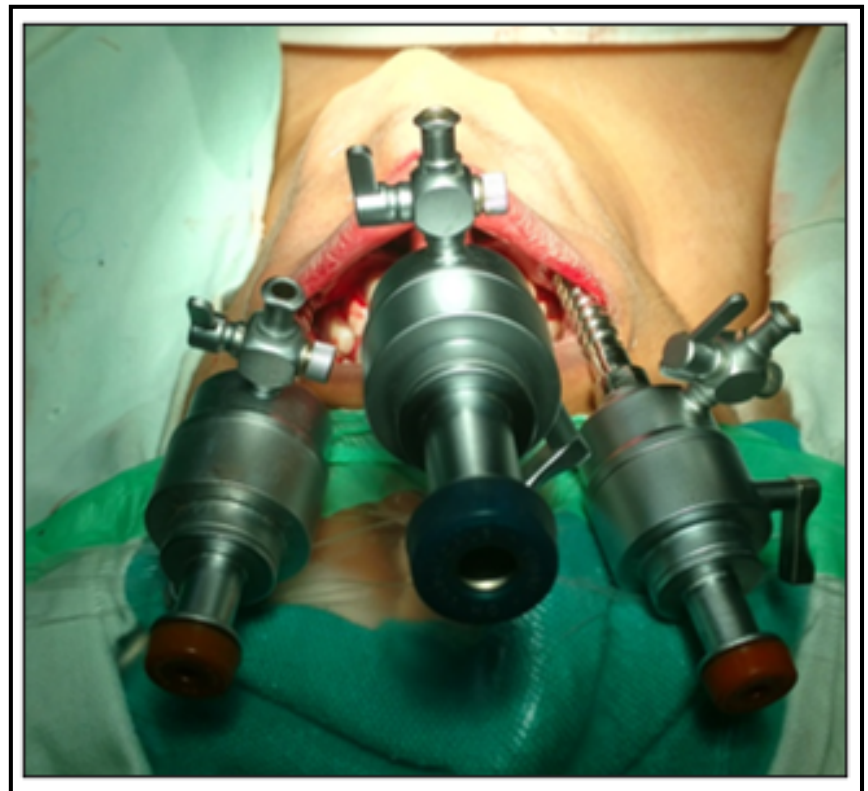

Fig. 1. Position of the telescope and side ports 


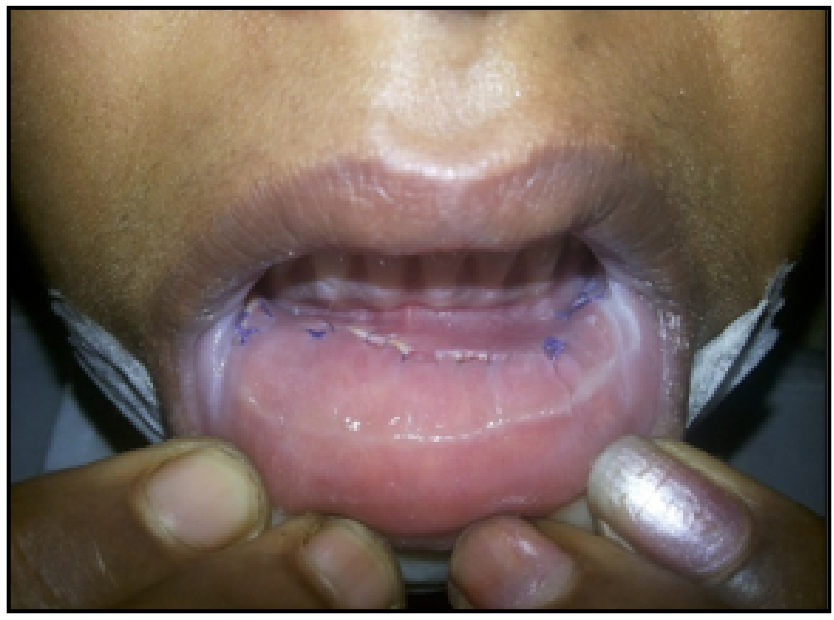

Fig. 2. The sub-labial incision line in the post-op photograph

sutured using a V-Loc ${ }^{\mathrm{TM}}$ technique by 3-0 vicryl ${ }^{\mathrm{TM}}$. The sub labial incisions were sutured with 3-0 vicryl. (Fig.2)

\section{Results:}

Two out of 3 patients did not develop any complication. Intra-operative blood loss was minimal (less than $100 \mathrm{cc})$. They were started on oral feeds on the same day. Post-operative pain was controlled adequately with intravenous analgesics. There was no evidence of recurrent laryngeal nerve or mental nerve injury. The patients did not develop any symptoms of hypocalcemia and the post-operative calcium was normal. They were discharged 4 days post-surgery. The patients felt satisfied with the surgery outcomes, especially the cosmetic result. (Fig.3)

One patient developed diffuse bleeding from the gland which could not be controlled. Thus, the decision was taken to convert it into an open procedure and the surgery was completed. The patient developed mild post-operative emphysema, however it spontaneously resolved within two days.

\section{Discussion}

The concept of natural orifice transluminal surgery (NOTES) for thyroid was developed by Witzel et al. ${ }^{4}$ A single $10 \mathrm{~mm}$ incision was made in the sublingual area for the telescope and two $3.5 \mathrm{~mm}$ incisions were made externally at the neck for instrumentation. They performed endoscopic transoral thyroidectomy on 10 living pigs and no complications were reported. Wilhelm et al. then developed the endoscopic minimally invasive thyroidectomy (eMIT). ${ }^{5}$ The centre port was a $10 \mathrm{~mm}$ port in the sublingual region and another $5 \mathrm{~mm}$ port was used at the oral vestibule. Of their 96 patients they had 1 transient RLN injury, 1 permanent RLN injury, 15 mental nerve injury, 6 infection, 3 conversion to open procedure. However, the sublingual approach involves violation of the floor of the mouth. On account of its technical difficulty and high complication rate, it has now fallen out of practice.

The oral vestibular approach was first described by Richmon et al. ${ }^{6}$ They placed all ports in the oral vestibule thus eliminating the sublingual port. Since then, the transoral vestibular approach has been used across various centres worldwide. The largest series reported so far is by Anuwong et al of 60 patients. Their recommendation for transoral endoscopic thyroidectomy vestibular approach is for: (I) benign thyroid disease with small to moderate thyroid nodules; (II) thyroid cancer which has 1-2 cm cancer nodules, and (III) Grave's disease limited to $10 \mathrm{~cm}$ in size. ${ }^{7}$

The main concern regarding taking a transoral approach for thyroidectomy is the possibility of

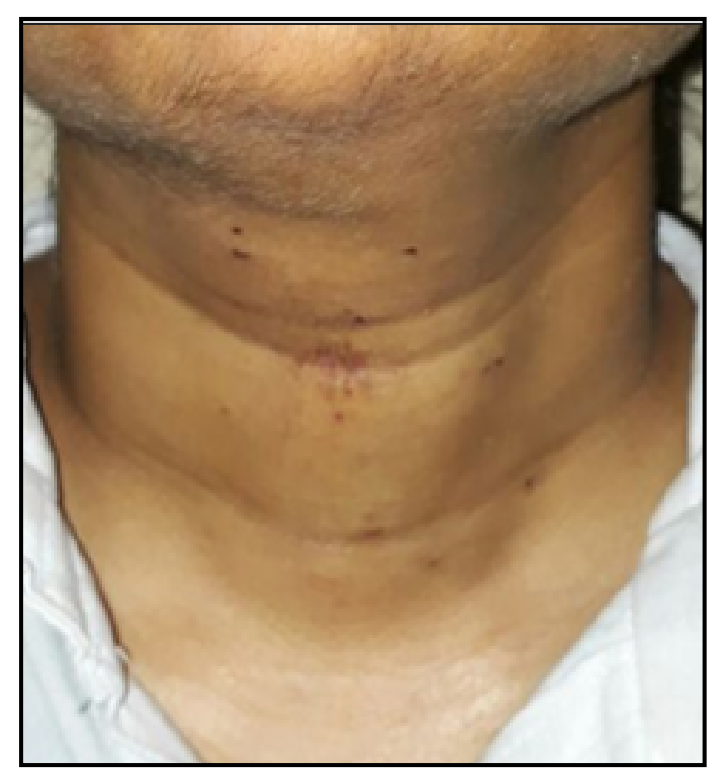

Fig. 3. The cosmetic outcome 
infection due to the commensals present in the oral cavity and injury to the mental nerve. However, our review of literature revealed that no such infection has been reported in any series. The injury to the mental nerve is avoided by staying in the subcutaneous plane and leaving adequate tissue on the mandible.

In our early experience we have found that accessing the gland, dissecting around the gland and achieving haemostasis with the right instruments is feasible. Retraction of the strap muscles to separate the lateral border of the gland is a surgical challenge and the external stitch taken in the neck is extremely useful to delineate the lateral border of the gland. Apart from cosmesis, the other advantage of this technique is better vision since the capsular dissection can be performed with a high definition camera system with better illumination and magnification.

Contra-indication of the procedure at present would be thyroid swellings with neoplastic etiology, whereas size of the swelling would be relative contraindication depending upon the experience of the author.

\section{Conclusion}

The transoral thyroidectomy by vestibular approach is feasible and promising, providing truly a 'scarless' and 'minimally invasive' approach. As the experience of the surgeons improve, we will be able to tackle larger swellings too in the future.

\section{References}

1. Hannan SA. The magnificent seven: a history of modern thyroid surgery. Int J Surg. 2006;4(3):187-91

2. Miccoli P, Ambrosini CE, Materazzi G, Fregoli L, Fosso LA, Berti P. New technologies in thyroid surgery. Endoscopic thyroid surgery. Minerva Chir. 2007; 62(5):335-49

3. Patel D, Kebebew E. Pros and Cons of Robotic Transaxillary Thyroidectomy. Thyroid. 2012; 22(10):984-5

4. Dio nigi G, Rovera F, Boni L. Commentary on transoral access for endoscopic thyroid resection: Witzel K, von Rahden BH, Kaminski C, Stein HJ. Transoral access for endoscopic thyroid resection. Surg Endosc. 2008; 22(8):1871-5. Surg Endosc. 2009 Feb 6 [cited 2017 Oct 30]; 23(2):454-5; discussion 456

5. Wilhelm T, Metzig A. Video. Endoscopic minimally invasive thyroidectomy: first clinical experience. Surg Endosc. 2010; 24(7):1757-8.

6. Richmon JD, Pattani KM, Benhidjeb T, Tufano RP. Transoral robotic-assisted thyroidectomy: A preclinical feasibility study in 2 cadavers. Head Neck 2010 Jul 13; 33(3):n/a-n/a.

7. Anuwong A, Kim HY, Dionigi G. Transoral endoscopic thyroidectomy using vestibular approach: updates and evidences.

Gland Surg. 2017; 6(3):277-84. 